\title{
The Effect of an Aluminium Foil Shield on Reducing The Strength of Electromagnetic Radiation of Mobile Phones Reaching the Oculi of Adult Male Rats
}

\author{
Dion K. Dharmawan ${ }^{1,2}$, Viskasari P. Kalanjati ${ }^{3}$ and Abdurachman ${ }^{3}$ \\ ${ }^{I}$ Master in Basic Medical Science Degree Program, Faculty of Medicine, Universitas Airlangga, Jl. Mayjen Prof. Dr. \\ Moestopo 47, Surabaya, Indonesia. \\ ${ }^{2}$ Department of Anatomy and Histology, Faculty of Medicine, Universitas Jember,Jember, Indonesia. \\ ${ }^{3}$ Department of Anatomy and Histology, Faculty of Medicine, Universitas Airlangga,Indonesia. \\ dion.fk@unej.ac.id
}

Keywords: $\quad$ Aluminium Foil, Electromagnetic Radiation, Malondialdehyde, Mobile Phones, Oculi.

\begin{abstract}
Mobile phones produce electromagnetic radiation (EMR) whilst transmitting data. The EMR can generate the oxidative stressors that might affect the oculi of the mobile phone users. Aluminium foil (AF) has been proposed as a shield against EMR because it has the potential to cause absorption loss and reflection loss. This study investigates whether the AF can reduce the mobile phone's EMR as an oxidative stressor to the subjected rat oculi by measuring the malondialdehyde (MDA) levels and comparing these to the controls. Thirty-two adult male rats were divided equally into 4 groups $(n=8)$. Groups K1 and K2 were the control groups with and without AF by respectively, as were study groups in groups $\mathrm{P} 1$ and $\mathrm{P} 2$. The rats in the study groups were exposed to EMR from a mobile phone with specificity absorption rate $0.84-1.86 \mathrm{~W} / \mathrm{kg}$ in standby mode and connected to Wi-fi for 4 hours daily for 30 days. The MDA levels of the right oculus were measured using spectrophotometry. Data was analysed by Kruskal-Wallis test (SPSS v.23). The MDA levels in groups III and IV was higher than in groups I and II; it was significantly highest in group III compared to the others with significance level of $p<0.05$. Groups I and II had no significant modulation in the MDA levels. This study demonstrated that AF could be a shield against EMR, and that was shown by the lower levels of the MDA in the shielded subjects.
\end{abstract}

\section{INTRODUCTION}

Electromagnetic radiation (EMR) has been known to have adverse effects on biological tissue through the formation of free radicals. Cell phones use electromagnetic waves for data transmission purposes (Hamada, Singh and Agarwal, 2011). Today, telecommunication service providers use higher frequencies bandwidth (up to gigahertz) for fast internet data transmission in telecommunication (Kumar, 2013). The higher frequency band usage in electromagnetic waves tends to generate more energy radiation. The energy of electromagnetic waves absorbed by biological tissue can lead to formation of reactive oxygen species (ROS) that can damage lipids, proteins, and DNA (Hamada, Singh and Agarwal, 2011). ROS that bind to lipids in the form of polyunsaturated fatty acids (PUFAs) will result in residual products, one of which is malondialdehyde (MDA). MDA is often used as an indirect oxidative stress reaction marker because it is the one of end-products of oxidative stress and it has non-toxic properties (Ayala and Muñoz, 2014).

The amount of energy of electromagnetic wave radiation received by biological tissue is called the specific absorption rate (SAR) (Hasan Sallomi, 2012). The eyes (oculi) comprise a primary vision sensory organ that has a high electrical conductivity (Gandhi, Lazzi and Furse, 1996). The energy of electromagnetic wave radiation that is received by biological tissue is directly proportional to the electrical conductivity (Sallomi, 2012). In addition, human oculi were irreversible to tissue damage, so they become sensory organs whose high risk of hazard from the radiation of electromagnetic waves (Cejka and Cejkova, 2015). 
Several previous studies have proved that exposure to electromagnetic wave radiation can lead to thinning of the cornea and corneal epithelium thickness in mice and cataracts on the oculi of dogs and rabbits (Elder, 2003), as well as increased oxidative stress in macular degeneration of the retina (SanGiovanni and Chew, 2005).

Aluminium foil (AF) is a mild, thin and low-cost conductor material that can be considered to be a shield against electromagnetic wave radiation (Pratap et al., 2014). The effectiveness of the shield is determined by the amount of reflection loss, absorption loss, and internal reflection loss proportional to the high electrical conductivity and low magnet permeability (Cheung, 2009). AF has an electrical conductivity of $0.63 \mathrm{~S} / \mathrm{m}$ and a magnet permeability of $1 \mathrm{H} / \mathrm{m}$ (Cheung, 2009). The effectiveness of AF against electromagnetic wave radiation is still not known.

\section{METHODS}

The type of this study is laboratory experimental research which has been approved by Bioetik Unit and Humanities Faculty of Medicine Universitas Airlangga (No. 167/ EC/ KEPK/ FKUA/ 2017). This research was conducted in July-August 2017 at Animal Laboratory of Medical Faculty of Universitas Airlangga. This study used 32 white rats (Rattus norvegicus) Wistar strains, whose weight was 200-300 grams and aged 2-3 months. A total of 32 rats were divided into 4 groups with each group consisting of 8 rats $(n=8)$. Group I (negative control) was a group of male Wistar rats that were not given exposure to EMR nor shielding AF. Group II (positive control) was a group that was not given exposure to EMR but was given shielding AF. Group III was a group given EMR exposure but not given shielding AF. Group IV was a group given exposure to EMR and given shielding AF. Prior to conducting the study, the 4 groups were acclimatized for 7 days in both the care cage and the exposure cage. Food and drink were given to male Wistar rats ad libitum in equal amounts for each group.

The source of electromagnetic wave radiation was cell phone GSM 2100 (frequency $2100 \mathrm{MHz}$ ) (Taiwan) with SAR $0.84-1.86 \mathrm{~W} / \mathrm{Kg}$ in standby mode and connected to Wi-fi (wireless fidelity). The influence of $\mathrm{AF}$ on the electric field and magnetic field of the mobile phone was measured before conducting research using GM 3120-EN-00 Electromagnetic Radiator Tester (Benetech, China).
The thickness of the AF coating fold was determined to reduce EMR by half of the initial doses. The duration of daily radiation was 4 hours continuously for 30 days. During the radiation of electromagnetic waves, the rats were placed in a plastic container measuring $20 \times 16 \times 9 \mathrm{~cm}$, which was covered by a wood-framed fencing wire. A mobile phone was taped to the inner floor of this plastic box container and covered with a plastic bag, which was coated with plastic mica. In group IV, AF was placed under the plastic mica and above the phone to prevent damage to the AF.

After 30 days, the rats were prepared to be harvested. The rats were anesthetized using ketamine. After anesthetization, the right oculi of the rats were removed by surgery and then transferred into the Eppendorf tube. The examination of MDA levels began with the calibration of standard solutions. Fresh eye tissue was homogenized using mortar and stamper with added PBS buffer. Then homogenate was sentrifuged on $3000 \mathrm{rpm}$ for 15 minutes. A supernatant $(4 \mathrm{~mL})$ of homogenate was added by $1 \mathrm{~mL}$ TCA $15 \%$ and $1 \mathrm{~mL}$ of $0.37 \%$ TBA in $0.25 \mathrm{~N} \mathrm{HCl}$. Then, the preparation was heated at $80^{\circ} \mathrm{C}$ for $15 \mathrm{~min}$. After that, the preparation was cooled for 1 hour. Then the preparations are confused (concentrated) at $3000 \mathrm{rpm}$ for 15 minutes. After that, the supernatant was measured using spectrophotometry at $532 \mathrm{~nm}$ wavelength.

The reading of results used UV-VIS U-2810 Spectrophotometer Model: 122-000 No: 1819-011a (Hitachi, Japan). Measurement of MDA level was done twice. The absorbance data was converted to MDA concentration and tested statistically by comparative method using SPSS software version 23.

\section{RESULTS}

The results of measurements of MDA average levels in groups I, II, III and IV on spectrophotometers with wavelength $532 \mathrm{~nm} 2$ repetitions are shown in table 1 and figure 1.

Table 1: Descriptive data of mean MDA level examination results.

\begin{tabular}{ccc}
\hline Groups & Absorbance (OD) & $\begin{array}{c}\text { MDA concentration } \\
\text { level }(\mathrm{ng} / \mathrm{mL})\end{array}$ \\
\hline K1 & $0,062 \pm 0,015$ & $0,111 \pm 0,051$ \\
K2 & $0,082 \pm 0,024$ & $0,177 \pm 0,078$ \\
P1 & $0,148 \pm 0,029^{*}$ & $0,395 \pm 0,094^{*}$ \\
P2 & $0,085 \pm 0,022$ & $0,188 \pm 0,073$ \\
\hline
\end{tabular}

\footnotetext{
* highest results
} 
(data: mean \pm standard deviation)

The result of the normality test using the Shapiro-Wilk test shows that group II has abnormal data distribution ( $p$ value $<0,05)$. The results of the Kruskal-Wallis test and post hoc Mann-Whitney test showed that there were significant differences between group III and other groups (table 2 and table 3 ).

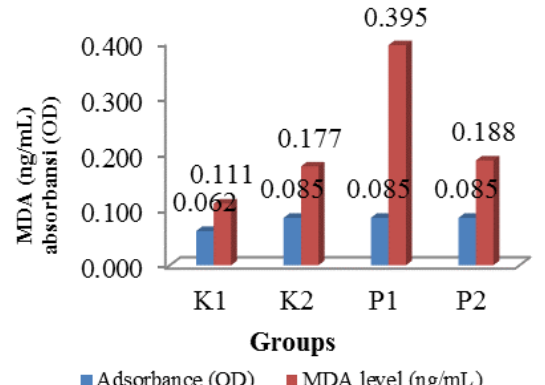

Figure 1: Bar chart of absorbance and MDA levels.

Table 2: Kruskal-Wallis test results of MDA level in rats' oculi.

\begin{tabular}{|c|c|c|}
\hline Variable & $p$ value & Explanation \\
\hline $\begin{array}{c}\text { Mean of MDA } \\
\text { level }\end{array}$ & $0,000 * * *$ & Significant \\
\hline
\end{tabular}

$p$ value is significant $* \mathrm{p}<.001$

Table 3: Mann-Whitney test results of MDA levels in rats' oculi between groups

\begin{tabular}{|c|c|c|c|}
\hline $\begin{array}{c}\text { Groups } \\
(\mathrm{I})\end{array}$ & $\begin{array}{c}\text { Groups } \\
(\mathrm{J})\end{array}$ & $\begin{array}{c}p \text { value of MDA } \\
\text { concentrations } \\
\text { mean }\end{array}$ & Explanation \\
\hline $\mathrm{K} 1$ & $\mathrm{~K} 2$ & 0.058 & Not significant \\
\hline & $\mathrm{P} 1$ & $0.001^{* *}$ & Significant \\
\hline & $\mathrm{P} 2$ & $0.046^{*}$ & Significant \\
\hline $\mathrm{K} 2$ & $\mathrm{~K} 1$ & 0.058 & Not significant \\
\hline & $\mathrm{P} 1$ & $0.003^{* *}$ & Significant \\
\hline & $\mathrm{P} 2$ & 0.529 & Not significant \\
\hline $\mathrm{P} 1$ & $\mathrm{~K} 1$ & $0.001^{* *}$ & Significant \\
\hline & $\mathrm{K} 2$ & $0.003^{* *}$ & Significant \\
\hline & $\mathrm{P} 2$ & $0.001^{* *}$ & Significant \\
\hline $\mathrm{P} 2$ & $\mathrm{~K} 1$ & $0.046^{*}$ & Significant \\
\hline & $\mathrm{K} 2$ & 0.529 & Not significant \\
\hline & $\mathrm{P} 1$ & $0.001^{* *}$ & Significant \\
\hline
\end{tabular}

$p$ value is significant $* p$ value $<.05 ; * * p$ value $<.01$.

\section{DISCUSSION}

The results of this study indicate that the highest MDA levels are present in the group receiving electromagnetic wave radiation without $\mathrm{AF}$, which is significantly different from that of the other groups. MDA is one of the markers of oxidative stress through the lipid peroxidation process, especially in unsaturated fatty acids (polyunsaturated acids) found in cell membranes (Ayala and Muñoz, 2014). The oculi comprise one of the high-risk organs that interact directly with the EMR produced by the phone especially during the calling mode (Hamada, Singh, and Agarwal, 2011). The oculi have higher electrical conductivity and permittivity than other head organs, increasing the risk of damage caused by EMR exposure (Gandhi, Lazzi, and Furse, 1996). In the oculi, lipid peroxidation has an important role in degenerative oculi disease (age-related macular degeneration, cataracts, glaucoma, diabetic retinopathy) (Njie-Mbye et al., 2013).

Electromagnetic wave radiation triggers an increase in the activity of the mitochondria so that it will form an amount of free radicals or ROS that are more excessive than the antioxidant enzymes formed in the oculi (De Iuliis et al., 2009). This unbalanced increasing of ROS will lead to oxidative stress conditions that result in lipid peroxidation, protein denaturation, and DNA damage (Ayala and Muñoz, 2014). The exposure to cell phone radiation with a frequency of 900 Megahertz (MHz) and SAR of 1.2 $\mathrm{W} / \mathrm{kg}$ at $4 \times 10$ minutes per day in standby conditions and resting phases for 30 days could lead to oxidative stress on corneal and lens oculi tissue by increasing oxidative stress markers significantly, such as MDA, superoxide dismutase (SOD), glutathione peroxidase (GSH-Px), and catalase (CAT) (Balci, Devrim and Durak, 2007).

Continuous exposure to EMR over long periods of time will lead to changes in the structure and function of the oculi tissue, which can lead to decreased thickness of the anterior corneal epithelial layer and corneal stroma; increased oxidative stress biomarkers in the cornea, lens and retina; and changes in the clarity of the lens (Balci, Devrim and Durak, 2007; Akar et al., 2013; Nita and Grzybowski, 2016).

In addition, the results of this study prove that AF can reduce oxidative stress due to EMR radiation. There is a significant difference between group III with group IV in MDA levels. The shielding effectiveness is determined by its potential to cause absorption loss $(\alpha \mathrm{A})$, and reflection loss $(\alpha \mathrm{R})$ for electric field and magnetic field. The conductivity factor and the electrical permeability and magnetization of an insulating material are directly proportional to the results of reflection losses $(\alpha \mathrm{R})$, absorption losses $(\alpha \mathrm{A})$, and internal 
reflection losses ( $\alpha$ IR) (Cheung, 2009). AF has good relatively magnetic permeability and electrical conductivity as conductor material, that is, $1 \mathrm{H} / \mathrm{m}$ and $0.63 \mathrm{~S} / \mathrm{m}$ (Cheung, 2009) respectively. The effectiveness of the shield depends on the depth of the skin. At 1 sheet of AF depth, electromagnetic wave radiation will lose about $63 \%$ of the energy (Pratap et al., 2014). To increase the effectiveness of the insulation against the magnetic field, AF must be arranged into several layers of depth (Pratap et al., 2014). AF does not effectively weaken magnetic fields (Pratap et al., 2014). This study proves that 1 layer of $\mathrm{AF}$ can reduce the electric field more than $1 / 100$ times from the initial value while to reduce the magnetic field by $1 / 2$ times from the initial value, it requires 10 layers of $\mathrm{AF}$. It also proves that $\mathrm{AF}$ is more effective to insulate an electric field than a magnetic field. Further research is needed to study $\mathrm{AF}$ as an insulating material and why it cannot be a magnetic field baffle at microwave frequencies.

\section{CONCLUSIONS}

EMR from cell phones can cause oxidative stress. This process increases lipid peroxidation processes (especially in PUFAs) that can be measured by elevated MDA levels. This study has proven that the groups of rats exposed to EMR without an AF shield had the highest levels of MDA due to lipid peroxidation process compared with other groups. The groups of rats exposed to EMR that used AF as shields had lower MDA levels. In this study, AF has been shown to reduce electromagnetic wave radiation through the potential of reflection loss, absorption loss, and internal reflection loss.

\section{ACKNOWLEDGMENTS}

Thank you to all lecturers in The Department of Anatomy and Histology, Faculty of Medicine, Universitas Airlangga, Surabaya, Indonesia, especially to Chairul Anwar, drh., MS., PA. Vet. (K); Dr. Ni Wajan Thirthaningsih dr., MS., PA. (K); and Dr. Joni Susanto, M. Kes for the guidance, encouragement and advice, and also my colleagues Dr. Irmawan Farindra and Dr. Etha Rambung for teamwork given during the study. Thank you to Faculty of Medicine, Universitas Jember, for study permission and assisting in the administration of scholarships.

\section{REFERENCES}

Akar, A. et al, 2013. 'Effects of low level electromagnetic field exposure at $2.45 \mathrm{GHz}$ on rat cornea', International Journal of Radiation Biology, 89(4), pp. 243-249. doi: 10.3109/09553002.2013.754557.

Ayala A, Muñoz MF, A. S, 2014. 'Lipid Peroxidation: Production, Metabolism, and Signaling Mechanisms of Malondialdehyde and 4-Hydroxy-2-Nonenal', Oxidative medicine and cellular longevity, 2014, p. 360438. doi: http://dx.doi.org/10.1155/2014/360438.

Balci, M., Devrim, E. and Durak, I, 2007. 'Effects of mobile phones on oxidant/antioxidant balance in cornea and lens of rats', Current Eye Research, 32(1), pp. 21-25. doi: 10.1080/02713680601114948.

Cejka, C. and Cejkova, J., 2015. 'Oxidative stress to the cornea, changes in corneal optical properties, and advances in treatment of corneal oxidative injuries', Oxidative Medicine and Cellular Longevity, 2015. doi: $10.1155 / 2015 / 591530$.

Elder, J. A., 2003. 'Ocular Effects of Radiofrequency Energy', Bioelectromagnetics, 24(SUPPL. 6), pp. 148-161. doi: 10.1002/bem.10117.

Gandhi, O. P., Lazzi, G. and Furse, C., 1996. 'EM Absorption in the Human Head and Neck for Mobile Telephones', IEEE Transactions on Microwave Theory and Techniques, pp. 1884-1897.

Hamada, A. J., Singh, A. and Agarwal, A., 2011. 'Cell Phones and their Impact on Male Fertility: Fact or Fiction', The Open Reproductive Science Journal, 3(216), pp. 125-137. doi: 10.2174/1874255601103010125

Hasan Sallomi, A., 2012. 'A Theoretical Approach for SAR Calculation in Human Head Exposed to RF Signals', Journal of Engineering and Development, 16(164), pp. 1813-7822.

De Iuliis, G. N. et al., 2009. 'Mobile phone radiation induces reactive oxygen species production and DNA damage in human spermatozoa in vitro', PLOS ONE, 4(7). doi: 10.1371/journal.pone.0006446.

Kumar, A., 2013. 'Comparision of 3G Wireless Networks and 4G Wireless Networks ':, 6(1), pp. 1-8.

Nita, M. and Grzybowski, A., 2016. 'The Role of the Reactive Oxygen Species and Oxidative Stress in the Pathomechanism of the Age-Related Ocular Diseases and Other Pathologies of the Anterior and Posterior Eye Segments in Adults', Oxidative Medicine and Cellular Longevity, 2016. doi: 10.1155/2016/3164734.

Njie-Mbye, Y. F. et al., 2013. 'Lipid peroxidation: Pathophysiological and pharmacological implications in the eye', Frontiers in Physiology, 4 DEC(December), pp. 1-10. doi: 10.3389/fphys.2013.00366.

SanGiovanni, J. P. and Chew, E. Y., 2005. 'The role of omega-3 long-chain polyunsaturated fatty acids in health and disease of the retina', Progress in Retinal and Eye Research, 24(1), pp. 87-138. doi: 10.1016/j.preteyeres.2004.06.002.

Pratap, S. Khatri, J. Jain, P. dan Banga, D., 2014. 'Electromagnetic Stress - A Danger to Human 
The Effect of an Aluminium Foil Shield on Reducing The Strength of Electromagnetic Radiation of Mobile Phones Reaching the Oculi of Adult Male Rats

Health', International Journal of Emerging

Technologies in Computational and Applied Sciences, 14-832: 305-309.

Cheung, C. S., 2009. 'Shielding Effectiveness of Superalloy, Aluminum, and Mumetal Shielding Tapes'.

Sunnyvale, California. The Faculty of California

Polytechnic State University at San Luis Obispo. 